\title{
ANALISE DOS PRINCIPAIS RISCOS ASSOCIADOS AO BANHO DE MAR NA PRAIA DO FUTURO, FORTALEZA-CEARÁ
}

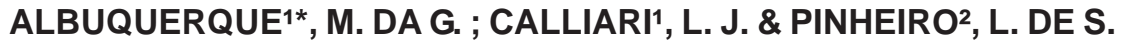 \\ 1- Universidade Federal do Rio Grande. Laboratório de Oceanografia Geológica. Av. Itália Km 08, \\ Campus Carreiros, Rio Grande, RS. CEP 96.201-900, Brasil.migueldaguia@gmail.com; \\ tsclauro@furg.br \\ 2- Universidade Federal do Ceará. Instituto de Ciências do Mar - LABOMAR. Av. Abolição, 3207, \\ Fortaleza, CE. CEP 60.165-081, Brasil. lidriana.Igco@gmail.com \\ *Corresponding author: migueldaguia@gmail.com
}

\begin{abstract}
ALBUQUERQUE, M. DA G. ; CALLIARI, L. J. \& PINHEIRO, L. DE S. 2010. Analysis of major risks associated with sea bathing at Futuro beach, Fortaleza - Ceará. Braz. J. Aquat. Sci. Technol. 14(1): 1-8. ISSN 1808-7035. This work presents natural hazards (permanent and non-permanent) related to beach bathing, as well as to social use of Futuro beach in Fortaleza city (Ceará stae, Northeast Brazil). In order to obtain such informations it was necessary classify beach type through topographic surveys and grain size analysis and combining them with beach accidents and public usage. Data were collected in two phases and include historical data from life-guards (years 2002 to 2006), and field surveys carried out from November of 2004 to September of 2005. Field data consisted of in situ observation of morphodynamic characteristics, as well as information given by life-guards regarding beach bathing accidents. Studies about the user's profile and morphodynamics features showed that the highest rates of accidents were recorded among male victims aged between 21 and 28 years (59\%). Most of the rescues occurred at profile $04(66 \%)$, during the transition between the high and low water, associated with transverse bar and rip and low tide bar rip morphodynamic stages. Data obtained from life-guards showed that rip currents were identified as the most important hazard for bathers ( $86 \%$ of cases). According to the morphodynamic behavior of Futuro beach, the best appropriate method for improve beach safety is preventive education.
\end{abstract}

Keywords: Beach safety, rip currents, beach morphodynamics.

\section{INTRODUÇÃO}

Os ambientes praiais se caracterizam por serem os mais democráticos que existem uma vez que são locais de recreação e lazer, caracterizando assim o litoral como um fator econômico importante para determinados países. Quando as praias passam a agrupar um fluxo muito grande de pessoas, em função dos fortes investimentos comerciais e turísticos, tendem a oferecer riscos associados ao banho de mar. Segundo Leal (2006) as potencialidades para as atividades recreacionais são as principais razões para a expansão urbana e ocupação territorial e a não industrialização das áreas costeiras do Brasil.

Os termos perigo e risco tem se tornado cada vez mais freqüentes no vocabulário científico (Berribilli et al., 2007), embora nesse estudo assumam significados diferentes. O perigo está associado diretamente ao ambiente praial em si. Ele restringe-se as características físicas da praia, sem envolver o público usuário (Berribilli et al., 2007). Short (1991, 1999) estabelece dois tipos de perigos: os sazonais e os permanentes. O primeiro refere-se, principalmente, as mudanças no comportamento dos bancos arenosos, canais e variação e intensidade das correntes costeiras. O segundo tipo trata de feições geológicas presentes na localidade, no caso desse estudo, as rochas de praia. O risco é o somatório entre os tipos de perigos existentes e o número de pessoas no ambiente praial. Dal Cin \& Simeoni (1994) e Dolan \& Walker (2004) consideram risco como sendo a maior ou menor exposição das estruturas ou da população a eventos que podem causar danos. Os riscos dependem diretamente do perigo, pois consideram a presença de valores humanos e materiais ligados a ele (Berribilli et al., 2007).

O Estado do Ceará tem uma forte vocação turística, atraindo muitos turistas nos períodos de alta estação, que correspondem aos meses de julho, dezembro e janeiro. Contudo, apesar do sucesso das praias como locais de recreação, estas representam perigos potenciais de diferentes categorias, particularmente para aqueles que tomam banho de mar (Klein et al., 2003).

Por ano cerca de 490.000 pessoas morrem em conseqüência de afogamentos no mundo levando em consideração somente as ocorrências notificadas (Benedet et al. 2003). Segundo Klein et al. 2003 afogamentos são a terceira causa de morte no Brasil, considerando todas as idades e todos os ambientes aquáticos. No Brasil, estudos relacionados à segurança dos banhistas são pouco difundidos, contudo destacam-se 
os trabalhos pioneiros realizados pelo Centro de Educação Superior de Ciências da Terra e do Mar-CTTMar, na costa de Santa Catarina, nos períodos de alta estação. O programa implementado pelo CTTMar, na costa catarinense segue a base dos modelos empregados na Austrália e Nova Zelândia.

Os determinantes dos níveis de risco público de uma praia estão associados à intensidade, tipo de uso que recebem e de suas características morfodinâmicas (Hoefel \& Klein, 1998). Embora tenha havido um crescimento no número de trabalhos científicos relacionados à saúde, o turismo, a segurança e o gerenciamento do litoral (Klein et al., 2003), os trabalhos relacionados aos usuários da praia e sua segurança no banho de mar ainda são escassos. O presente estudo tem como objetivo caracterizar os principais riscos associados ao banho de mar na praia do Futuro propondo ações mitigatórias para redução dos índices de acidentes na localidade.

A área de estudo (Figura 1) encontra-se inserida na Região Metropolitana de Fortaleza. Com seus 08 km de extensão, a praia do Futuro destaca-se por apresentar boas condições de balneabilidade em relação às outras praias da Região Metropolitana. Contudo, o local é reconhecido como sendo um dos de maior risco ao afogamento. $O$ ambiente é caracterizado como sendo de meso-maré com variação relativa da maré em torno de $3,1 \mathrm{~m}$. A localidade é caracterizada pela presença de sedimentos bimodais e polimodais com topografia tridimensional bem desenvolvida, destacandose também pelo forte fluxo turístico além da intensa atividade de comércio.

\section{MATERIAIS E MÉTODOS}

Os aspectos metodológicos consideram dois parâmetros: as características ambientais da praia e a percepção dos usuários. As características ambientais foram trabalhadas a partir dos dados coletados entre os anos de 2004 e 2006. Perfis topográficos foram realizados com base na metodologia proposta por Birkemeier (1985) com auxílio de uma estação total modelo Topcom e um prisma. As leituras foram feitas nos pontos de inflexão (pós-praia, estirâncio e zona de surfe) da morfologia praial.

Os dados referentes à altura significativa $(\mathrm{Hs}) \mathrm{e}$ período de pico (Tp) das ondas foram coletados a partir de observações visuais. Para medição de Hs foi utilizada uma mira topográfica, com graduação de $5 \mathrm{~m}$, posicionada na zona de arrebentação. Observações sucessivas foram realizadas com intuito de retirar um universo amostral significativo de dados. Em relação às medições de $T p$, um cronômetro digital foi utilizado pra registrar a passagem de onze ondas em um deter-

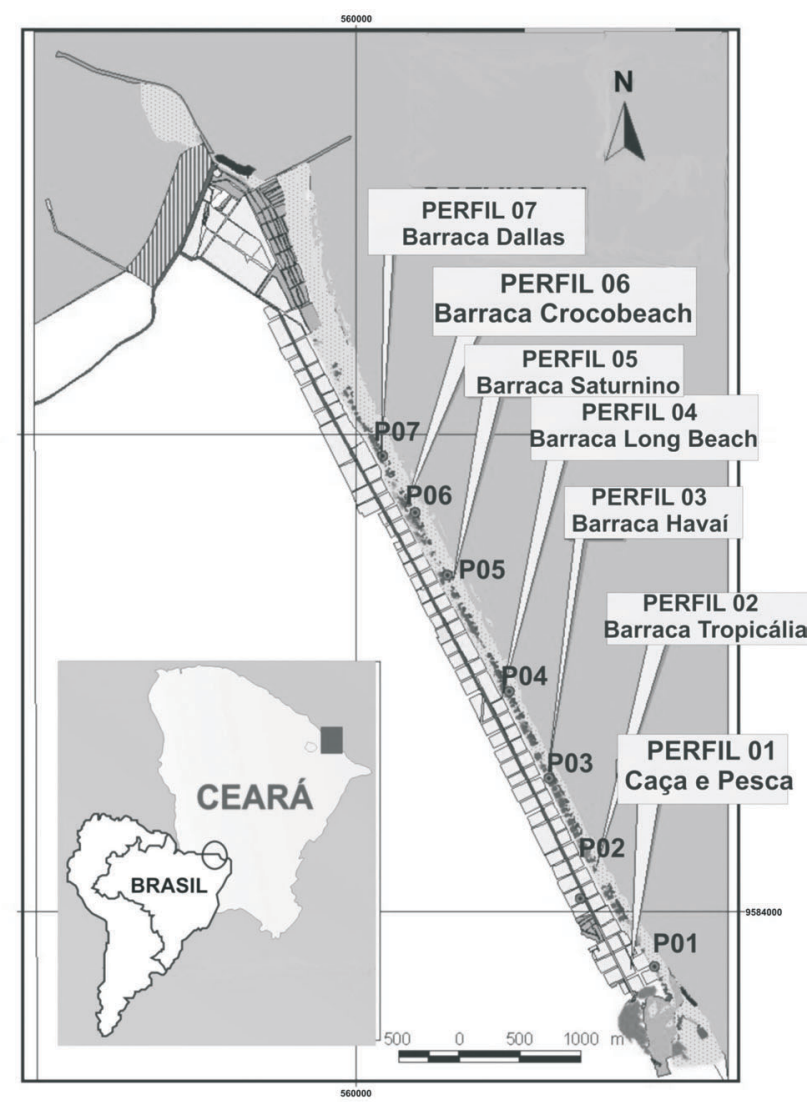

Figura 1. Mapa de localização da área de estudo.

minado campo de visão. As amostragens de sedimentos foram realizadas nos dias 24/11/2004, 25/01/2005, 21/07/2005 e 20/09/2005, na região do pós-praia, estirâncio e zona de surfe, em sete pontos de coleta, totalizando 84 amostras, que foram submetidas a análises granulométricas e posteriormente ao tratamento estatístico por métodos gráficos de Folk \& Ward (1957).

A classificação morfodinâmica utilizada nesse estudo foi baseada nos trabalhos de Masselink \& Short (1993); Masselink (1994) e Masselink \& Hegge (1995) nas praias australianas submetidas aos regimes de meso e macro-marés. Masselink \& Short (1993) levando em consideração as mudanças ocorridas no ambiente praial em virtude das variações na amplitude da maré, criaram o Parâmetro Relativo da Maré que é definido por:

$$
\mathrm{RTR}=\frac{\mathrm{TR}}{\mathrm{Hb}}
$$

Onde TRé a amplitude da maré na fase de sizígia e Hb é a altura média da onda na arrebentação. Para esse estudo se utilizou a escala de valores que variam de $3>R T R<15$, as quais são caracterizadas por con- 
dições de ondas ou marés dominantes. Os valores de RTR $>15$, citados na classificação de Masselink \& Short (1993) não se aplicam a esse estudo, pois caracterizam ambientes de planícies de maré e, os mesmo não são identificados na localidade estudada (Tabela 1).

Para o cálculo de ômega (Ù), os valores de velocidade média de decantação das partículas sedimentares (Ws) foram extraídos da tabela de Raudkivi (1990) onde a mesma foi calculada a partir da equação de Gibbs et al. (1971), introduzindo-se as correções calculadas para grãos naturais segundo a equação de Baba \& Komar (1981). A escolha da tabela se atribuiu ao fato da mesma ter servido de base para os estudos de Pinheiro (2000) na praia da Caponga, litoral leste do Ceará.

O perfil do usuário foi obtido em parceria entre a Universidade Estadual do Ceará - UECE e o Corpo de Bombeiros e foi constituído de três etapas: (1) aplicação de questionários com intuito de caracterizar os usuários que freqüentam a localidade; (2) coleta dos dados de ocorrências por afogamentos e (3) tratamento estatístico dos dados. A área de estudo foi dividida em sete pontos de monitoramento os quais, segundo dados da brigada militar, apresentam a maior quantidade de registros de afogamentos.

Os questionários foram aplicados no período de novembro de 2004 e nos meses de janeiro, julho e setembro de 2005. Os períodos de levantamento correspondem às épocas de alta estação na capital cearense. Foram aplicados 40 questionários em cada um dos sete pontos monitorados, totalizando 280 questionários por levantamento e 1120 ao longo do estudo. As perguntas foram elaboradas no Laboratório de Geologia e Geomorfologia Costeira e Oceânica - LGCO da UECE, com base no estudo feito por Klein et al. (2003) nas praias do litoral de Santa Catarina. Os questionamentos visavam avaliar o perfil

Tabela 1. Caracterização dos diferentes tipos de estágios morfodinâmicos a partir do Parâmetro Relativo da Maré. Adaptado de Masselink \& Short (1993).

\begin{tabular}{|c|c|c|}
\hline AMPLITUDE RELATIVA & GRUPO & TIPO DE PRAIA \\
\hline & & 1. Reflectivo \\
\hline \multirow[t]{2}{*}{ RTR $<3$} & Onda dominante & 2. Intermediário \\
\hline & & 3. Dissipativo \\
\hline \multirow[t]{2}{*}{$3<R T R<15$} & & 4. Terraço de baixa-mar \\
\hline & & 5. Banco/corrente de baixa- \\
\hline (2) RTR $<7$ & Interação onda-maré & mar \\
\hline \multirow[t]{2}{*}{ (3) $\mathrm{RTR}<15$} & & 6. Ultra-dissipativa \\
\hline & & 7. Transicional (praia para \\
\hline RTR $>15$ & Maré dominante & planície de maré) \\
\hline
\end{tabular}

socioeconômico, procedência, grau de familiaridade com a praia e percepção das principais transformações ambientais. Os dados estatísticos de afogamentos foram cedidos pelo Corpo de Bombeiros do Estado do Ceará onde, os mesmos englobam levantamentos referentes aos períodos compreendidos entre os anos 2000 e 2006 em toda a orla da capital.

\section{RESULTADOS E DISCUSSÃO}

\section{Número de acidentes/Resgates}

Nos anos de 2002 e 2003, segundo o Corpo de Bombeiros, os percentuais de mortes por afogamento foram de 3\% e 4\%, respectivamente. Em 2004 esses percentuais tiveram uma redução significativa, alcançando o patamar de $0,8 \%$ no número de vítimas fatais. Nos anos subseqüentes esses índices voltaram a subir, e em 2006 chegaram à margem de 6,38\%, o maior índice registrado desde 2002.

Levando em consideração os registros de afogamentos mensais, sem vítimas fatais (Figura 2), os gráficos mostram que as maiores ocorrências foram registradas nos meses de dezembro, janeiro e julho; período de alta estação na capital cearense. A exceção foi em março de 2003 quando foi registrado um número de ocorrências semelhantes às encontradas nos períodos de maiores incidências. Em detrimento do elevado número de salvamentos na área surgiu o projeto "De olho no mar", uma iniciativa do Corpo de Bombeiros em parceria com instituições de ensino superior do estado. A iniciativa visava o monitoramento das principais áreas de risco da orla cearense. Em 2003 foi lançado um projeto piloto onde foram instaladas 08 torres de vigilância para os salva-vidas, nas imediações da praia do Futuro. Em 2004, um ano após a instalação das torres de vigilância, os registros de acidentes sem vitimas fatais reduziram de 298 para 149 casos.

A diminuição no número de ocorrências pode estar relacionada ao fato dos usuários se concentrarem nas imediações das localidades que eram cobertas pelas guaritas dos salva-vidas, facilitando assim um possível resgate. Mesmo com a presença de postos salva-vidas, os índices de resgates sem vítimas fatais voltaram a subir nos anos subseqüentes (2005 e 2006) chegando ao maior patamar com 470 casos registrados (Figura 3).

Esta elevação nos índices pode estar associada ao aumento do fluxo de turistas a cada ano, ao aumento do número de estabelecimentos comercias que se localizam fora do raio de cobertura postos salva-vidas e a difusão dos banhistas ao longo da praia com a abertura de novos estabelecimentos. A partir do comparativo entre o total de ocorrências na localidade e o 


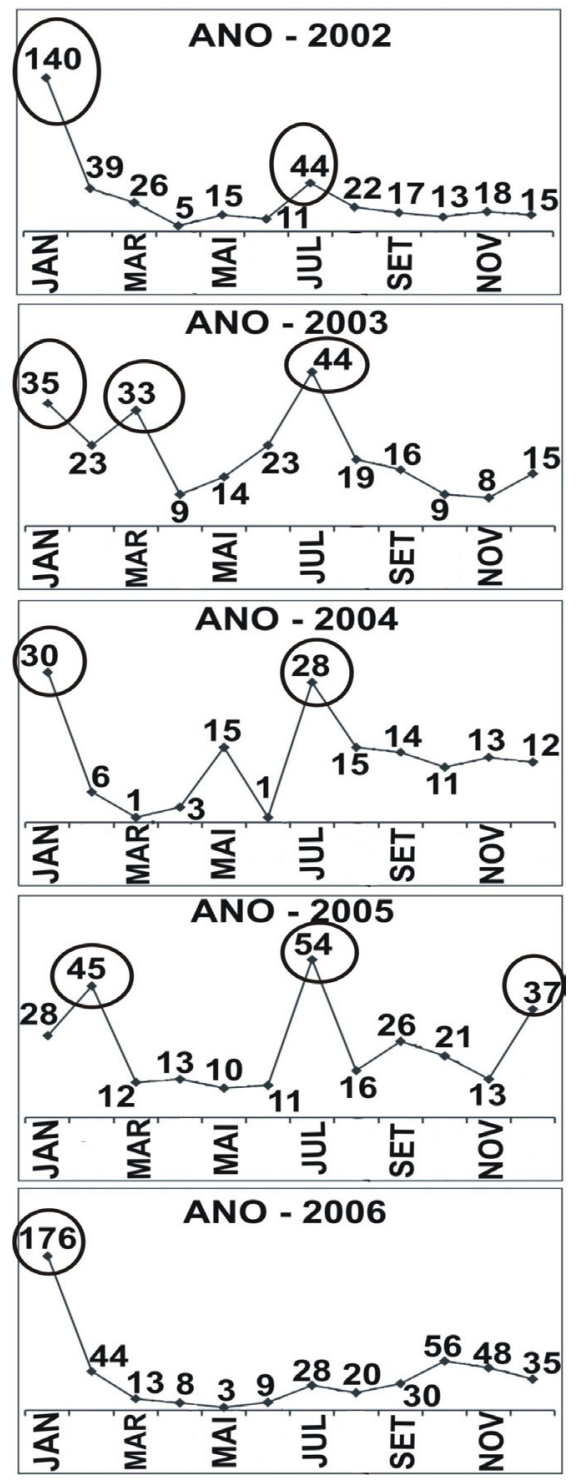

Figura 2. Perfil mensal do número de afogamentos entre os anos de 2002 e 2006.

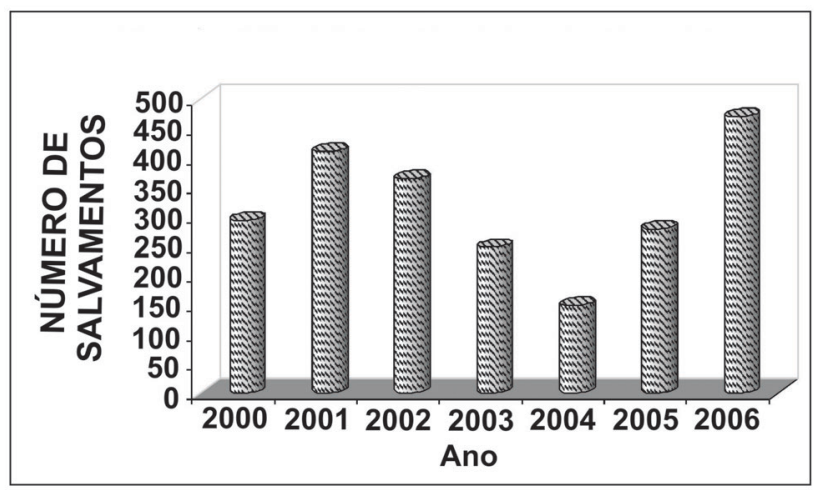

Figura 3. Evolução do número de salvamentos entre 2002 e 2006. somatório dos registros do restante das praias da $\mathrm{Re}-$ gião Metropolitana (Figura 4) observou-se que, em 2004, o número de salvamentos efetuados na praia do Futuro superava o número de resgates nas demais praias da capital.

\section{Tipos de Perigos e Riscos}

A partir dos questionários aplicados na praia do Futuro foram listados, segundo os usuários, os quatro principais tipos de perigos relacionados ao banho de mar: correntes de retorno, cavas, ausência de salvavidas e rochas de praia (Figura 5). Segundo os usuários, as correntes de retorno abrangem o maior percentual de perigos dentre os demais fatores apontados (44\%). As cavas foram apontadas como sendo o segundo maior fator de perigo da localidade (38\%), seguidos pela ausência de salva-vidas (16\%) e da presença de rochas de praia (2\%). Segundo dados da brigada militar, a maior parte dos salvamentos ocorreu na transição entre a preamar e a baixa-mar e geralmente entre sexta-feira e domingo; no período compreendido entre as $10 \mathrm{~h} 00 \mathrm{~min}$ da manhã e 16h30min da tarde. Os dados dos salvavidas apontam que, um percentual significativo das ocorrências (86\%) foi registrado em situações onde os banhistas foram apanhados pelas correntes de retorno sendo que em virtude desta porcentagem, as mesmas podem ser reconhecidas como principal fator de risco no que diz respeito ao elevado número de acidentes na localidade.

Short \& Hogan (1994), num estudo realizado na costa australiana, discutem que na transição da preamar para a baixa-mar as correntes de retorno tornamse mais fortes à medida que a profundidade dos canais aumenta. Segundo Short \& Hogan (1994), em ambientes de meso-maré, as correntes de retorno estão associadas somente com bancos na maré baixa.

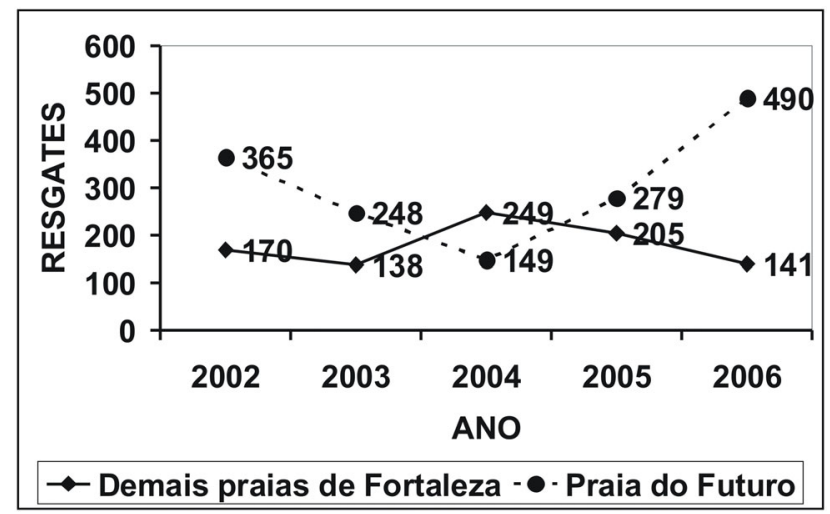

Figura 4. Comparativo entre o número de salvamentos na praia do Futuro com as demais praias da capital. 


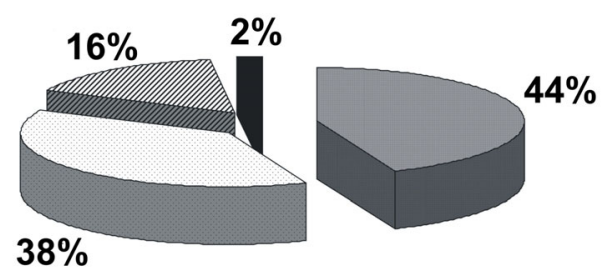

\section{Correntes de retorno \\ Cavas \\ Ausência de guarda-vidas $\square$ Rochas de Praias}

Figura 5. Principais riscos associados ao banho de mar segundo os usuários.

Em relação às rochas de praia (Figura 6), estas são detectadas apenas na localidade denominada Caça e Pesca (Ponto 01). Devido às oscilações da maré, os arenitos de praia ficam encobertos durante o período de preamar. A partir do momento em que eles não são perceptíveis, estes podem ser potencialmente perigosos para banhistas desavisados ou que desconhecem o local.

\section{Morfodinâmica Associada aos Acidentes de Banho}

O perfil 04, localizado nas proximidades da barraca Long Beach foi enquadrado como sendo o ponto mais susceptível a acidentes de banho. A localidade responde por $66 \%$ dos acidentes e é caracterizada pelo surgimento de canais de profundidade média em torno de $1,1 \mathrm{~m}$ situados aproximadamente entre $70 \mathrm{~m}$ e $120 \mathrm{~m}$, a partir do marco topográfico estabelecido no pós-praia, e aproximadamente a $77 \mathrm{~m}$ da linha de praia (Figura 7). Os sedimentos da localidade apresentaram uma

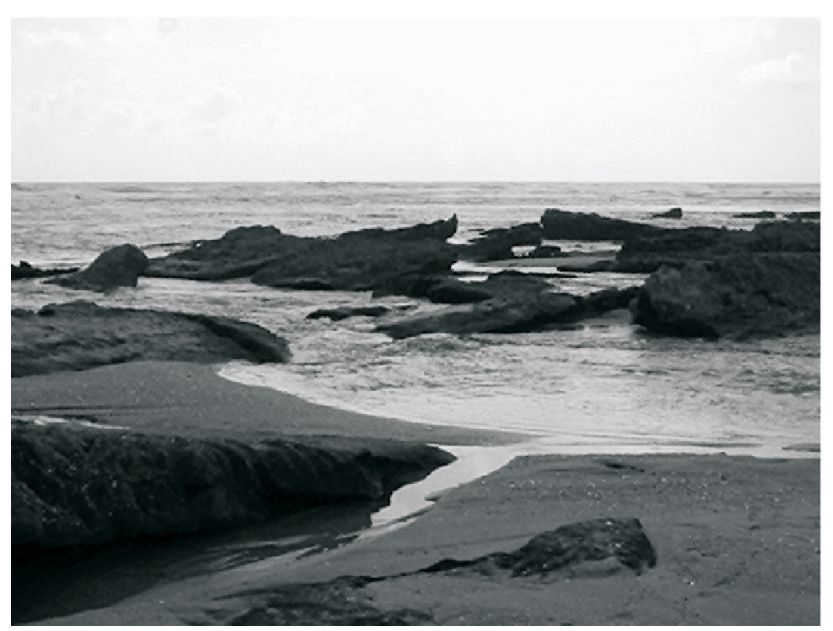

Figura 6. Rochas de praia na região do Caça e Pesca (Perfil 01). Fonte: arquivo pessoal.
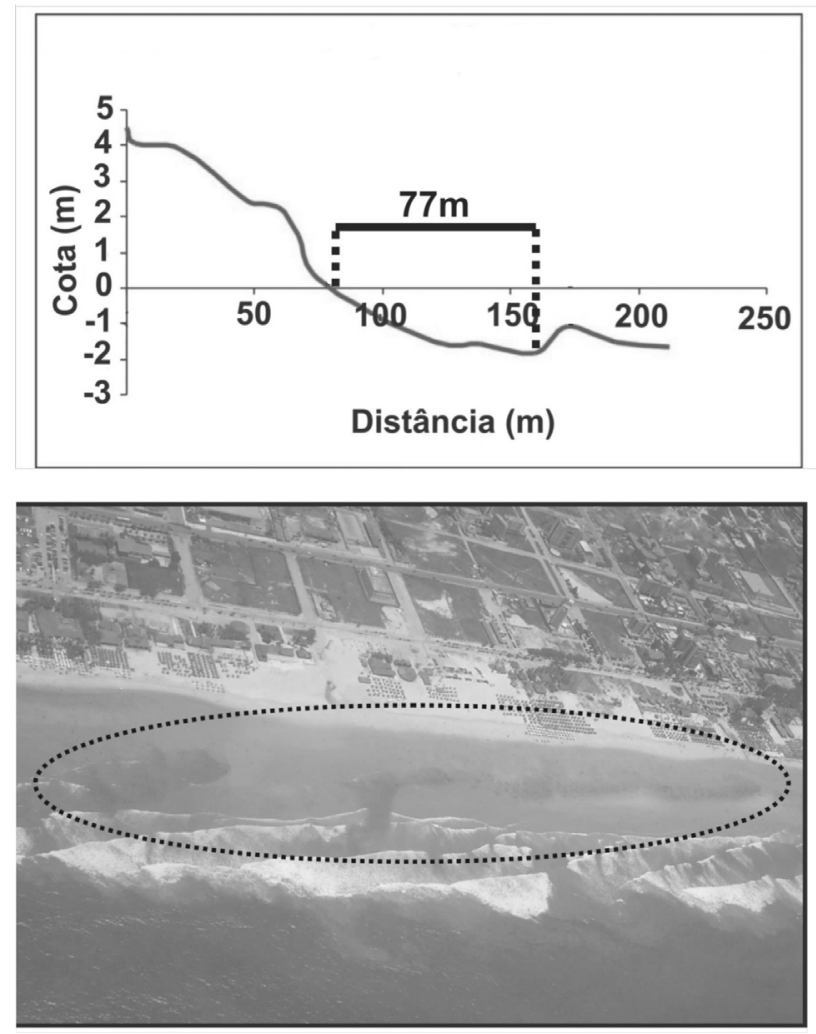

Figura 7. Distância aproximada da primeira cava em relação à linha de costa.

granulometria média, com características bimodais e moderadamente selecionadas.

A extensão máxima do perfil ficou em torno de $160 \mathrm{~m}$ com ondas incidindo obliquamente em direção à costa com angulo de $97^{\circ}$ provindo de E-SE e altura média em torno de $0,95 \mathrm{~m}$. A largura da zona de surfe mede aproximadamente $105 \mathrm{~m}$ e, em relação ao estagio morfodinâmico, a localidade enquadrou-se nos estados intermediários barra transversal, segundo a classificação de Masselink \& Short (1993), nos meses de novembro de 2004, janeiro e setembro de 2005; e no estado banco/corrente de baixa-mar no mês de julho de 2005. Em ambos os estágios, a praia apresenta condições reflectivas no período de preamar e variações, principalmente na porção inferior da face de praia e zona de surfe, na baixa-mar; acompanhada da formação de canais com profundidades variando ao longo do estudo entre $0,42 \mathrm{~m}$ e $1,1 \mathrm{~m}$.

O estágio barra transversal é caracterizado pela presença de fortes correntes de retorno; nesse tipo de estágio os bancos arenosos persistem por mais tempo junto à costa. O estágio banco/corrente de baixa-mar é caracterizado por arrebentação do tipo deslizante ou mergulhante e evidencia-se a presença de correntes de retorno na maré baixa. Nesse estágio as barras migram em menor intensidade (Masselink \& Hegge, 1995). 

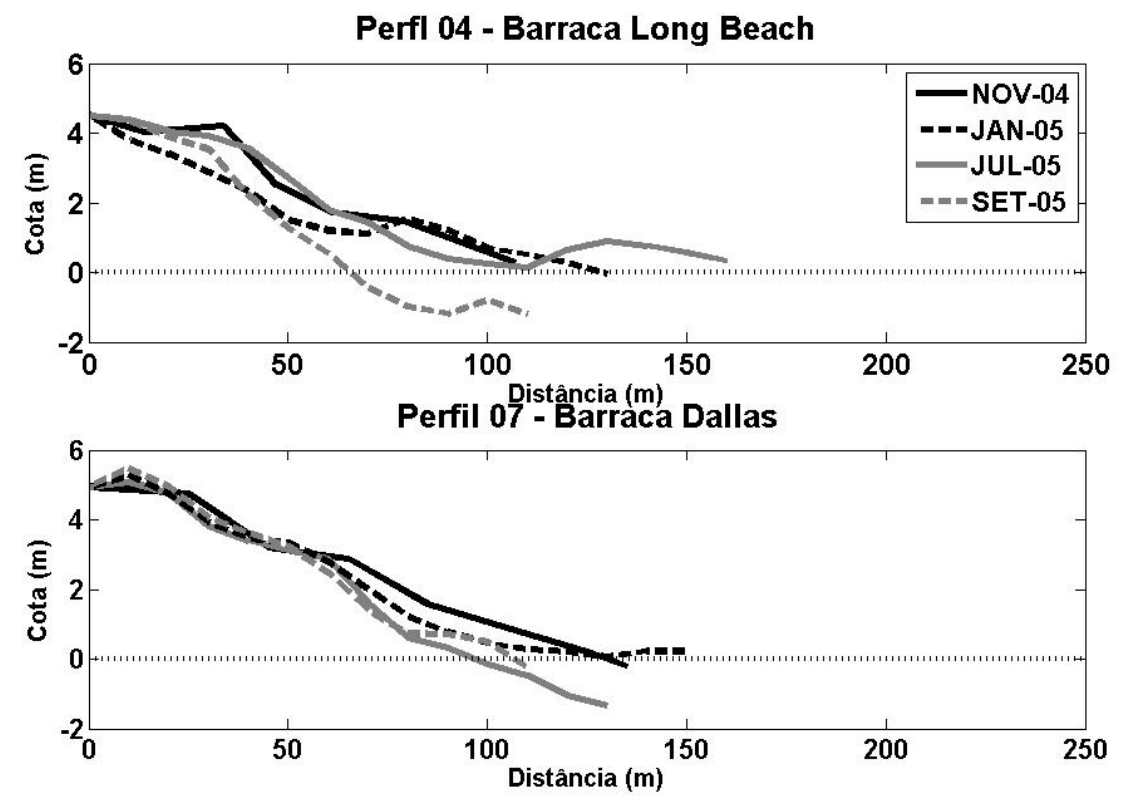

Figura 8. Perfis topográficos dos pontos de maior e menor registro de acidentes por correntes de retorno.

O ponto 07 , localizado nas proximidades da Barraca Dallas, responde pelo menor índice de ocorrências no que diz respeito a acidentes com e sem vítimas fatais $(4,3 \%)$; caracterizando-se como a localidade menos perigosa aos usuários. No local não foi registrada a presença de canais nos meses monitorados. Os sedimentos apresentaram granulometria fina nos três primeiros meses do estudo, na porção do estirâncio e da zona de surfe; e tamanho médio de grão para o mês de setembro de 2005 na zona de espraiamento. Todas as amostras classificaram-se como bem selecionadas. A direção de ondas ficou em torno de $88^{\circ}$ E-SE e a altura média das ondas na arrebentação apresentou valor médio de $0,8 \mathrm{~m}$.

A extensão máxima do perfil foi de $155 \mathrm{~m}$ com inclinação média do estirâncio de $3^{\circ}$ e largura da zona de surfe com aproximadamente $130 \mathrm{~m}$. No que diz respeito ao estágio morfodinâmico, a localidade enquadrou-se no estágio ultra-dissipativo, segundo a classificação proposta por Masselink \& Short (1993), nos meses de novembro (2004), janeiro e julho (2005); e no estágio terraço de baixa-mar no mês de setembro (2005). O estágio ultra-dissipativo caracteriza-se por possuir arrebentação do tipo deslizante com presença de fracas correntes de retorno. A zona de surfe é extremamente dissipativa com muitas linhas de quebras. A inclinação da zona de espraiamento é muito suave e a zona de surfe é bastante energética. O estágio terraço de baixa-mar a face de praia é mais reflectiva e fracas correntes de retorno podem estar presentes. Variações em reflectividade e dissipação estão associadas às fa- ses de maré sendo a praia dissipativa em maré baixa e reflectiva em maré alta.

Dentre os sete pontos monitorados (Figura 8), o ponto 04 foi caracterizado como mais perigoso ao banho de mar tendo em vista que a localidade caracteriza-se por apresentar uma maior variação hidrodinâmica e por apresentar uma morfologia mais tridimensional em relação às outras localidades. Os sedimentos são do tipo areias médias bimodais e proporcionam a formação de feições de fundo (canais e barras) de grande variabilidade e mobilidade. Essas feições são enquadradas na categoria de riscos sazonais e são responsáveis pelo desenvolvimento de correntes de retorno mais freqüentes próximo a costa. Uma abordagem semelhante foi discutida por Calliari \& Klein (1993), em estudos realizados na costa sul do Rio Grande do Sul, onde os autores discutem que praias intermediárias e de granulometria média são consideradas como sendo as mais perigosas para os banhistas.

Fatores referentes à má sinalização e a um baixo contingente de salva-vidas podem ser apontados como fatores responsáveis pela elevação no número de ocorrências. O perfil traçado para as vítimas indica que grande parte dos usuários (59\%) tinha faixa etária entre 21 e 28 anos e pertencia ao sexo masculino. A partir dos questionários foi listado um grupo de cuidados e preocupações que os usuários procuram adquirir antes de entrar no mar (Tabela 2). Os banhistas nomearam 09 itens de cuidados para este estudo sendo que em primeiro lugar ficaram os indivíduos que tomam banho de mar somente nas proximidades da zona de espraiamento (32\%). É importante salientar que os cui- 
dados ou precauções dos usurários antes de entrar no mar são relevantes, pois muitos afogamentos acontecem, não só pela dinâmica praial, mas também por negligência dos banhistas em relação aos cuidados necessários neste ambiente. Em segundo e terceiro lugar ficaram respectivamente os usuários que observaram maré e a altura das ondas; e a correnteza. Os banhistas que preferem não entrar no mar ficaram no percentual de $9 \%$. Fatores como a preocupação na identificação de cavas, a não ingestão de bebidas alcoólicas, existência de afloramentos rochosos e a observação na busca de salva-vidas também foram listadas pelos usuários. Um dado muito importante é que uma pequena parcela dos entrevistados afirmou não observar nenhum tipo de risco. Bons resultados nesta temática foram obtidos por Leal (2006) na praia da Boa Viagem, Pernambuco.

\section{CONCLUSÕES}

O estudo conclui que o principal tipo de perigo associado à praia do Futuro são as correntes de retorno, as quais são responsáveis por $86 \%$ das ocorrências, principalmente nos pontos localizados próximos a barraca Long Beach (Ponto 04). A localidade é caracterizada por sedimentos médios bimodais, altura média das ondas de $0,95 \mathrm{~m}$ e variações laterais na morfologia, através da remobilização das feições de fundo (mobilidade dos bancos arenosos), induzindo gradientes laterais na altura da arrebentação que contribuem para formação das correntes de retorno. Durante o estudo, o ponto 04 se apresentou como sendo a localidade mais susceptível a acidentes com banhistas (66\% das ocorrências) onde, a maioria das vítimas é em geral do sexo masculino (59\%), com idade entre 21 e 28 anos. A maior parte dos acidentes (com e sem vítimas fatais) ocorreu na transição entre a preamar e a baixa-mar, quando a praia enquadrava-se nos estágios morfodinâmicos barra transversal e banco/corrente de baixa-mar, com variações principalmente na porção inferior da face de praia e zona de surfe; e presença de canais com profundidades variando entre $0,42 \mathrm{~m}$ e $1,1 \mathrm{~m}$.

A elevação nos índices de afogamentos pode estar relacionada à má distribuição das torres de segurança, tendo em vista que são 08 guaritas ao longo da orla, ou ao baixo contingente de salva-vidas destinado a uma área de $08 \mathrm{~km}$. O aumento do número de turistas na cidade de Fortaleza é um fator que pode ser levado em consideração para a elevação nos índices de afogamentos. Conclui-se também que grande parte dos usuários da praia, ao se dirigirem para o mar, não se preocupam com os aspectos relacionados a segurança de praia. Sem informações precisas sobre os riscos relacionados à localidade, os banhistas acabam tendo a falsa impressão de que a praia do Futuro é segura para o banho de mar. A maior parte das ocorrências ocorre nos meses de julho, dezembro e janeiro, períodos de alta estação na capital cearense. A implantação de uma melhor sinalização a respeito das condições de segurança da praia e aos riscos de banho e a realização de campanhas educativas através de panfletos e cartilhas faz-se necessário na tentativa de reduzir o numero de ocorrências. Pelas características das áreas monitoradas e educação preventiva é o método mais adequado para diminuição dos riscos e acidentes no uso das praias.

\section{AGRADECIMENTOS}

Os autores agradecem: Ao Major Barreto e ao Cabo Auricélio Matos do Corpo de Bombeiros do Estado do Ceará que disponibilizaram os dados relacionados aos números de afogamentos nas praias de Fortaleza; a equipe do Laboratório de Geologia e Geomorfologia Costeira e Oceânica - LGCO da Universidade Estadual do Ceará pela colaboração na aplicação dos questionários; ao Laboratório de Oceanografia Geológica - LOG da Fundação Universidade Federal do Rio Grande onde foram realizados os levantamentos estatísticos; ao MSc. Rafael Guedes pelas contribuições para melhoria do artigo; a CAPES pela bolsa de mestrado e ao CNPq e FUNCAP (processo № 996/ 03) pelo apoio financeiro junto ao projeto.

\section{REFERÊNCIAS}

Baba, J. \& Komar, P.D. 1981. Measurements and analysis of settling velocities of natural quartz sand grains. Journal of Sedimentary Petrology, 51(2): 631640.

Benedet, L.; Finkl, C.W. \& Klein, A.H.F. 2003. Morphodynamic classification of beaches on the atlantic coast of Florida: geographical variability of beach types, beach safety and coastal hazards. Journal of Coastal Research. 39 (SI): 360-365.

Berribilli, M.P.; Klein, A.H.F. \& Menezes, J.T. 2007. Riscos associados ao banho de mar. Estudo de caso da praia do Atalai, SC. Revista Brasileira de Geomorfologia. 7: 97-105.

Birkemeier, W.A. 1985. A User's guide to ISRP: The interactive survey reduction program. Instructions report CERC 84-11. U. S. Army Engineer Waterways Experimento Station. Coastal Engineering Research Center, Vicksburg, Missisipi, 101p.

Calliari, L.J. \& Klein, A.H.F. 1993. Características morfodinâmicas e sedimentológicas das praias oceânicas entre Rio Grande e Chuí, RS. Pesquisas. 20 (1): 48-56. 
Dal Cin, R. \& Simeoni, U. 1994. A Model for determining the classification, vulnerability and risk in the southern coastal zone of the Marche (Italy). Journal of Coastal Reseacrh. 10(1): 18-29.

Dolan, A.H. \& Walker, I.J. 2004. Understanding vulnerability of coastal communities to climate change related risks. Journal of Coastal Research, 39 (SI): 1316-1323.

Folk, R.L. \& Ward, W.C. 1957. Brazos river bar: a study in the significance of grain size parameters. Journal of Sedimentary Petrology, 27(1): 03-26.

Gibbs, R.T.; Mathew, M.D. \& Link, D.A. 1971. The relationship between size and sorting velocity. Journal Sedimentary Petrology, 41: 07-18.

Hoefel, F.G. \& Klein, A.H.F. 1998. Environmental and social decision factors of beach safety in the central northern coast of Santa Catarina, Brazil. Notas Téc. FACIMAR. 2: 155-166.

Klein, A.H.F; Santana, G.G.; Diehl, F.L. \& Menezes, J.T. 2003. Analysis of hazards associated with sea bathing: results of five years work in oceanic beaches of Santa Catarina state, southern Brazil. Journal of Coastal Research. 35 (SI): 107-116.

Leal, M.M.V. 2006. Percepção dos usuários quanto a erosão costeira na praia de Boa Viagem. Tropical Oceanography. 31(1): 39-52.

Masselink, G. \& Short, A.D. 1993. The effect of tide range on beach morphodynamics: a conceptual beach model. Journal of Coastal Research. 9: 785800.

Masselink, G. 1994. Morphodynamics of macrotidal beaches: examples from central Queensland, Australia. PhD Thesis. Coastal Studies Unit, University of Sydney, 272p.

Masselink, G. \& Hegge, B. 1995. Morphodynamics of meso and macrotidal beaches: examples from central Queensland, Australia. Marine Geology. 129: 123.

Pinheiro, L.S. 2000. Compatibilização dos processos morfodinâmicos e hidrodinâmicos com o uso e ocupação da praia da Caponga - Cascavel - CE. Dissertação de Mestrado. Universidade Estadual do Ceará, 164p.

Raudkivi, A.J. 1990. Loose Boundary Hidraulics. Ed. Pergamon - UK, $3^{\mathrm{a}}$ ed.

Short, A.D. 1991. Macro - meso tidal beach morphodynamics - An overview. Journal of Coastal Research. 7: 417-436.

Short, A.D. \& Hogan, C.L. 1994. Rip currents and beach hazards: their impact on public safety and implications for coastal management. Journal of Coastal Research. 12 (SI): 197-209.

Short, A.D. 1999. Beach hazards and safety. In: Short, A.D. (ed.) Handbook of beach and shoreface morphodynamics. Jonh Wiley \& Sons. 293-303 pp.
Wright, L.D. \& Short, A.D. 1984. Morphodynamic variability of beaches and surf zones: A synthesis. Marine Geology. 56: 92-118.

Submetido: Maio/2008 Revisado: Junho/2008 Aceito: Outubro/2008 